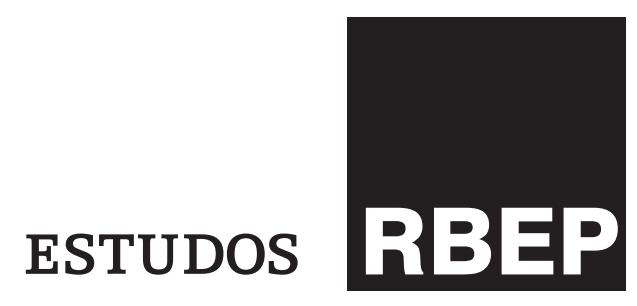

\title{
Estudantes do ensino médio e o ensino superior: explicitando o modus operandi dos bolsistas do Programa Institucional de Bolsas de Iniciação Científica para o Ensino Médio*
}

\author{
Adriano de Oliveira ${ }^{\mathrm{I}, \mathrm{II}}$ \\ Lucídio Bianchetti ${ }^{\mathrm{III}, \mathrm{IV}}$
}

http://dx.doi.org/10.24109/2176-6681.rbep.100i255.3809

\section{Resumo}

Este artigo investiga a política de formação inicial de pesquisadores na educação básica e sua recontextualização na prática, com foco, em termos de empiria, no Programa Institucional de Bolsas de Iniciação Científica para o Ensino Médio (Pibic-EM) da Universidade Federal de Santa Catarina (UFSC), inserido no contexto da iniciação científica júnior. Analisa o modus operandi dos sujeitos com ênfase nos processos de seleção e nas razões da sua adesão/desistência ao programa. Realiza estudo de caso na UFSC, que desenvolve o Pibic-EM, e em dez escolas públicas em que foram entrevistados 46 sujeitos, entre orientadores, bolsistas, coorientadores/ professores das escolas e coordenadores institucionais do programa. O fator determinante para a escolha dos bolsistas foi a presença de um habitus e de disposições próximas das requeridas pelo campo acadêmico. Entre os motivos da desistência dos estudantes/bolsistas, destacam-se: o reduzido valor da bolsa; a exigência de trabalho/remuneração para auxiliar a família;

\footnotetext{
* Uma versão deste artigo foi apresentada no G11

- Política da Educação Superior, na $38^{\mathrm{a}}$ Reunião da Associação Nacional de Pós-Graduação e Pesquisa em Educação (ANPEd), na cidade de São Luís, no período de 1 a 5 de outubro de 2017.

Universidade Federal de Santa Catarina (UFSC). Florianópolis, Santa Catarina, Brasil. E-mail <adriano.deoliveira2@ gmail.com>; <http://orcid. org/0000-0001-9148-5581>.

II Doutor em Educação pela Universidade Federal de Santa Catarina (UFSC). Florianópolis, Santa Catarina, Brasil.

III Universidade Federal de Santa Catarina (UFSC). Florianópolis, Santa Catarina, Brasil. E-mail: <lucidio.bianchetti@ pq.cnpq.br >; <http://orcid. org/0000-0001-9748-5646>

IV Doutor em Educação pela Pontifícia Universidade Católica de São Paulo (PUC-SP). São Paulo, São Paulo, Brasil.
} 
as expectativas da família em relação à trajetória acadêmica; o excesso de atividades escolares; e o baixo rendimento escolar.

Palavras-chave: critérios de seleção; desistência do aluno; ensino médio; Pibic.

\section{Abstract}

High school students and higher education: clarifying the modus operandi of the grantees in the Institutional Program of Scholarships for Undergraduate Research (Programa Institucional de Bolsas de Iniciação Científica - Pibic)

This study deals with policies for the training of basic education researchers and the reframing of its context; focused, empirically speaking, on Brazil's Institutional Program of Scholarships for Undergraduate Research (or, in Portuguese, Programa Institucional de Bolsas de Iniciação Científica Pibic -EM) from the Federal University of Santa Catarina (Universidade Federal de Santa Catarina - UFSC), within the Junior Scientific Training. The modus operandi of the research subject is analyzed with an emphasis on the selection processes and in the motivations for subscribing or dropping-out of the program. A case study is carried within UFSC, which involves the Pibic-EM, and in ten public institutions in which 46 subjects donated interviews, among advisors, grantees, co-supervisors/educators in the school and program intitutional coordinators. The aspect guiding the selection of grantees was the verification of a habitus and of a show of dispositions more inclined to the academia. Among the motivations pointed for dropping-out are:the limited value of the grant; the need to work to finantially support their family; their family's expectations regarding their academic trajectory; excessive school activities, and their poor performance in school.

Keywords: selection processes; student's drop-out; supervision; high school; Pibic.

\section{Resumen}

Estudiantes de la enseñanza secundaria y la enseñanza superior: explicitando el modus operandi de los becarios del Programa Institucional de Becas de Iniciación Científica para la Enseñanza Secundaria

Este artículo investiga la política de formación inicial de investigadores en la educación básica y su recontextualización en la práctica, con foco, en términos de empírea, en el Programa Institucional de Becas de Iniciación Científica para la Enseñanza Secundaria (Pibic-EM) de la Universidad 
Federal de Santa Catarina (UFSC), insertado en el contexto de la iniciación científica junior. Analiza el modus operandi de los sujetos con énfasis en los procesos de selección y en las razones de su adhesión/desistimiento al programa. Realiza un estudio de caso en la UFSC, que desarrolla el Pibic-EM, y en diez escuelas públicas en que fueron entrevistados 46 sujetos, entre orientadores, becarios, coorientadores/profesores de las escuelas y coordinadores institucionales del programa. El factor determinante para la elección de los becarios fue la presencia de un habitus y de disposiciones próximas a las requeridas por el campo académico. Entre los motivos del desistimiento de los estudiantes/becarios se destacan: el reducido valor de la beca; la exigencia de trabajo/remuneración para ayudar a la familia; las expectativas de la familia en relación a la trayectoria académica; el exceso de actividades escolares; y el bajo rendimiento escolar.

Palabras clave: criterios de selección; desistimiento del alumno; enseñanza secundaria; Pibic.

\section{Introdução}

O Programa Institucional de Bolsas de Iniciação Científica para o Ensino Médio (Pibic-EM), criado em 2010, é implementado pelas universidades e pelos institutos de pesquisa com o objetivo de "fortalecer o processo de disseminação de informações e conhecimentos científicos e tecnológicos básicos" e "desenvolver atitudes, habilidades e valores necessários à educação científica e tecnológica dos estudantes do ensino médio" (Brasil. CNPq, [2010]). O programa é voltado à educação científica e à identificação de jovens talentos, estimulando os estudantes a seguirem a carreira acadêmica. O crescimento da iniciação científica júnior (ICJ) evidencia uma mudança nas diretrizes do fomento à pesquisa, pois o Conselho Nacional de Desenvolvimento Científico e Tecnológico (CNPq), historicamente, concede bolsas de formação à pós-graduação (PG) stricto sensu e à graduação. Com essas ações, o alcance da iniciação científica (IC) e do Pibic foi estendido, passando a abranger ensino médio e profissional dentro das discussões e das políticas de formação de pesquisadores.

Neste texto, analisamos essa política de formação inicial de pesquisadores por meio da ICJ direcionada a estudantes da educação básica (EB). Buscamos identificar, em um contexto específico, as manifestações dos desafios de materializar a ICJ na EB e da aproximação entre esta e a educação superior (ES). Nesse sentido, investigamos os significados de condutas dos sujeitos envolvidos com o Pibic-EM na Universidade Federal de Santa Catarina (UFSC): os efeitos ou as contribuições intencionais, não intencionais e irrefletidas que suas práticas oferecem à reprodução ou transformação das configurações macro e microssociais e escolares, ou melhor, o seu modus operandi, apropriando-nos do conceito utilizado por Bourdieu (1983). 
Para muitos autores, uma forte barreira à constituição da perspectiva da pesquisa na EB é a preponderância de uma "educação bancária" (Freire, 2005), centrada na ação e no controle do professor nos processos de conhecimento. Essa postura pedagógica desestimula os estudantes a exercerem sua curiosidade, enfrentarem desafios cognitivos e construírem sua autonomia intelectual e afetiva. Acreditamos que a participação dos estudantes e de seus professores em pesquisas abre a possibilidade de uma descentração das ações docentes com ganhos para a formação - crítica e reflexiva - dos estudantes.

Concebemos a IC - tanto na graduação como no ensino médio - no contexto dos rituais de iniciação, passagem ou instituição. A IC pode ser considerada um ritual, pois se supõe que os estudantes não fazem parte, são "vistos 'como os de fora' porque são 'aprendizes'" (Calazans, 2002, p. 61) e, para serem introduzidos, para adquirirem o habitus, precisam passar por situações materiais e simbólicas que transformam o bolsista em alguém incluído, "de dentro". Dessa forma, o ritual aparta os "que já passaram por ele daqueles que ainda não o fizeram e, assim, institui uma diferença duradoura entre os que foram e os que não foram afetados" (Bourdieu, 1998, p. 97). Para Bourdieu, tais rituais instituem um "herdeiro", portanto a expressão mais apropriada talvez seja "ritos de instituição" ao invés de "ritos de passagem".

Os bolsistas do Pibic-EM - os "afetados" - constituem uma identidade que é a condição para serem aceitos e para sua permanência no campo acadêmico. O fato de serem aceitos mostra o reconhecimento do seu capital social e acadêmico, porém, acarreta obrigações e obediência a regras explícitas e implícitas do campo (Oliveira; Bianchetti, 2017). Há a obrigação e a incorporação de "um dever ser", de uma "segunda natureza", "sob a forma de habitus" (Bourdieu, 1998, p. 100). Há no campo acadêmico uma "crença que o sustenta", um "jogo de linguagem que nele se joga, das coisas materiais e simbólicas em jogo que nele se geram" (Bourdieu, 1998, p. 69), portanto, uma disputa por retornos materiais e simbólicos. Desse modo, podemos afirmar que tanto a IC quanto a ICJ são portas de entrada para o campo acadêmico. Os iniciantes necessitam ter disposição para aprender o jogo e aceitar as suas regras, desvendando a "caixa-preta" da pesquisa científica (Filipecki; Barros; Elia, 2006). Dessa maneira, concretizar a IC "é adentrar um espaço habitado por professores, pesquisadores e demais estudantes e seguir uma determinada etiqueta que poderá formá-lo como um pesquisador no futuro, é começar seu processo de formação em pesquisa" (ScorsoliniComin, 2014, p. 2).

Esta investigação aponta que a disposição dos bolsistas para entrar na área científica advém das recompensas materiais e simbólicas possibilitadas pela sua incorporação no campo acadêmico. O efeito ou a recompensa seriam o status e o capital social e educacional que podem ser obtidos com a constituição do bolsista como pesquisador, mesmo que iniciante, com efeitos positivos também no seu capital econômico. 


\section{Contexto da pesquisa: proposta metodológica}

A pesquisa empírica focalizou a implementação do Pibic-EM na UFSC, no período de 2010 a 2015. Por meio da vivência em quatro, dos cinco campi da UFSC, e em dez escolas públicas participantes do programa - sete estaduais, uma municipal e duas federais -, foram realizadas entrevistas com bolsistas, orientadores, coorientadores/professores da escola e coordenadores da IC da pró-reitoria de pesquisa da universidade. A Tabela 1 permite visualizar o número de bolsas concedidas, segundo campus e escola participante da pesquisa.

Tabela 1 - Número de bolsas distribuídas, segundo campus e escola (2010-2015)

\begin{tabular}{|c|c|}
\hline Localização & Bolsas distribuídas \\
\hline Campus I & 143 \\
\hline Escola A & 104 \\
\hline Escola B & 27 \\
\hline Escola C & 7 \\
\hline Escola D & 3 \\
\hline Escola E & 1 \\
\hline Escola F & 1 \\
\hline Campus II & 65 \\
\hline Escola G & 58 \\
\hline Escola H & 7 \\
\hline Campus III & 19 \\
\hline Escola I & 9 \\
\hline Escola J & 11 \\
\hline Campus IV & 35 \\
\hline Escola K & 18 \\
\hline Escola L & 5 \\
\hline Escola M & 6 \\
\hline Escola N & 6 \\
\hline Total & 262 \\
\hline
\end{tabular}

Fonte: Elaboração própria.

As 46 entrevistas foram conduzidas segundo a modalidade semiestruturada, em que "a relação que se cria é de interação, havendo uma atmosfera de influência recíproca entre quem pergunta e quem responde" 
(Ludke; André, 1988, p. 33). O critério para seleção dos sujeitos da pesquisa foi o envolvimento pedagógico e administrativo com o Pibic-EM da instituição de educação superior (IES). Assim, foram selecionados os bolsistas e os orientadores ${ }^{1}$ do programa, por estarem diretamente envolvidos com o ensino e com a aprendizagem das lides da pesquisa. Os coorientadores também foram escolhidos por auxiliarem no acompanhamento dos planos de atividades na escola e por contribuírem na seleção dos bolsistas; e os coordenadores da IES, por gerenciarem a implementação das bolsas e organizarem o processo de avaliação do programa.

Em razão das funções e das posições dos quatro grupos de sujeitos representados na pesquisa, organizamos quatro roteiros: para os bolsistas, o roteiro foi organizado em seis blocos e, para os orientadores, coorientadores e coordenadores institucionais, os roteiros foram estruturados em nove blocos. Neste texto, analisamos os resultados das questões dos roteiros que envolveram a discussão dos critérios de seleção dos bolsistas e as razões da escolha destes para o Pibic-EM, assim como os fatores que os levaram a desistir ou a ter sucesso no programa. A Tabela 2 apresenta a distribuição das entrevistas entre os sujeitos da pesquisa.

Tabela 2 - Distribuição de entrevistados, segundo campus e função

\begin{tabular}{|l|c|c|c|c|c|}
\multicolumn{1}{|c|}{ Campus } & Bolsista & Orientador & Coorientador & Coordenador & Total \\
\hline Campus I & 14 & 5 & 2 & 3 & 24 \\
\hline Campus II & 3 & 3 & 1 & & 7 \\
\hline Campus III & 4 & 1 & 1 & & 6 \\
\hline Campus IV & 6 & 2 & 1 & & 9 \\
\hline Total & 27 & 11 & 5 & 3 & 46 \\
\hline
\end{tabular}

Fonte: Elaboração própria.

Na análise das entrevistas, mobilizamos conceitos, como: aproximação entre níveis de ensino; praxis da pesquisa na EB; contexto de influência; meritocracia; exclusão; pertencimento; temporalidades institucionais; campo; ritos de iniciação científica na EB; uso do tempo; classes; habitus; ruptura; e capital social, econômico e cultural. Buscamos identificar as "manifestações de intersubjetividades e interações" dos sujeitos da pesquisa com o intuito de possibilitar "a criação de novos conhecimentos" (Cruz Neto, 1994, p. 51).

No próximo item, discutiremos o modus operandi dos participantes

As áreas de pesquisa dos orientadores foram: campus central - ciências humanas e educação; colégio de aplicação - matemática, língua portuguesa, química, artes, biologia, filosofia, física, geografia, história, sociologia e língua estrangeira; campus do interior - ciências exatas e da terra e engenharias. do Pibic-EM: os critérios, as formas de seleção e a adesão dos bolsistas; os aspectos referentes ao desinteresse e à desistência de participar do programa, seja por parte dos coordenadores da UFSC, seja dos (co) orientadores e estudantes das escolas. Esses elementos estruturantes emergiram da análise de conteúdo (Bardin, 1970) a que foram submetidas as entrevistas realizadas com os envolvidos no programa. 


\section{"Um prêmio para pessoas diferenciadas": da seleção e da adesão ao programa}

Com relação à seleção, constatamos que a escola, por meio do coorientador, tem atuação preponderante na indicação e na escolha inicial dos bolsistas. Um coorientador relata que "em princípio perguntava se eles tinham interesse em engenharia, porque era para a área mais das exatas". Então ele "chamava e entrevistava, falava do projeto, como iria funcionar."

Após a indicação da escola, o orientador e/ou os grupos de pesquisa fazem a ratificação da seleção e alguns esclarecimentos, como revela este depoente: "A escola indica e a gente faz uma boa conversa com eles para explicar o que é o trabalho, explicar os compromissos." O primeiro critério é o interesse, mas há também o da possibilidade de cumprir alguns compromissos semanais. Essa elucidação é realizada por alguns orientadores por meio de oficinas e reuniões. Além disso, entrevistas são feitas com a finalidade de apresentar nuances do campo científico, do Pibic-EM e do que é esperado dos bolsistas. Eles reconhecem a importância das ações para conhecimento sobre o programa, constituindo fatores à adesão ou não. Segundo um bolsista, esses encontros ajudam a "perder a curiosidade" sobre o que é o Pibic-EM e a formar o interesse pela IC.

Os depoimentos evidenciam os critérios de seleção: o interesse, a possibilidade de cumprir alguns compromissos e o interesse pela área vinculado às notas verificadas na análise do histórico escolar. São critérios que envolvem comportamentos e atitudes, que correspondem principalmente à autodisciplina e à disposição para realizar as tarefas relacionadas aos projetos de pesquisa. O depoimento de uma orientadora reproduz e amplia a perspectiva comportamental: o estudante "tem que ter força de vontade de ir atrás de algumas coisas e ter certa aptidão, não ter medo do novo."

Identificamos critérios e estratégias de seleção dos bolsistas relacionados ao conhecimento escolar, como: análise do histórico escolar, potencial e experiências anteriores com pesquisa, leitura e escrita. Excertos de falas de orientadores confirmam isso: "Eu faço a entrevista e procuro pautar interesses e experiências de leitura e de pesquisa" e "Focamos no edital, na avaliação do histórico escolar."

O depoimento de uma coordenadora do Pibic-EM demonstra a incorporação da ideologia do mérito e o reconhecimento de que há estudantes que não apresentam boas notas, mas demonstram potencial para o campo acadêmico:

Eu acredito na avaliação de mérito. [...] talvez só isso não seja suficiente. Mas infelizmęte é a forma mais objetiva que a gente tem de avaliar uma pessoa. As vezes como professora da graduação e da pós, nitidamente a gente tem estudantes que não têm um histórico, ou não tiraram as melhores notas durante uma disciplina, não frequentaram tanto como alguém que esteve $100 \%$ das aulas e que a gente vê que é um estudante brilhante. Mas essa avaliação é uma avaliação empírica do estudante. 
A Escola A (escola de aplicação) tem um contexto institucional e organizacional diferenciado pelo fato de os professores, por terem os títulos de mestrado e doutorado, atuarem também como orientadores, e de a IC ser uma diretriz curricular, inclusive com uma disciplina específica no $9^{\circ}$ ano. Logo, é possível que os orientadores e a coordenação da escola analisem as experiências anteriores e atuais com os bolsistas, favorecendo a escolha e a disputa dos estudantes que tenham "perfil de pesquisador" e potencial de escrita reconhecido. Segundo uma orientadora, os estudantes com esse perfil são "disputadíssimos". Em um dos campi, o orientador e o coorientador recorreram a psicólogos para ajudar na ratificação da escolha feita pelas escolas: "Eles conversaram com uma psicóloga. [...] Eles (estudantes) tinham que demonstrar certo interesse na hora da entrevista com a psicóloga."

Os sujeitos da pesquisa destacaram elementos do contexto social - como o capital social e econômico da família - que interferem na disponibilidade e no interesse do estudante e que contribuem para o afunilamento das possibilidades de se candidatarem e de se manterem no programa. Para um dos orientadores, por exemplo, "se a família dispõe de tempo de apoio, geralmente não é uma família muito miserável, porque a família dispensa o menino de trabalhar." Esse investimento familiar está implícito no processo de seleção e, muitas vezes, é determinante para a escolha dos estudantes.

Desse modo, é possível afirmar que na seleção prevalece a competência social sintetizada nos critérios comportamentais e modos de ser (habitus valorizado no contexto escolar e universitário), no capital social, educacional e econômico da família e na rede de relações do candidato a bolsista do Pibic-EM. Como afirma um orientador, "é a coisa um pouco do boca a boca; tu pega e encontra alguém que participa". A questão da competência científica também é levada em consideração, mas seu peso é relativo na escolha.

Fica evidenciado, nesta pesquisa, que os critérios e os processos de seleção dos bolsistas reproduzem, em grande parte, a escolha dos eleitos, dos já escolhidos, dos que possuem maior capital social, escolar e econômico, produzindo "os excluídos de dentro" (Bourdieu, 2003). O depoimento deste orientador expressa essa materialidade e ressalta a necessidade de, institucionalmente, a universidade e as escolas articularem processos para oportunizar aos "não eleitos" serem selecionados, rompendo com essa política de escolha:

A escola é uma entidade reprodutora do status quo de uma forma geral. [...] Então ela também escolhe aqueles primeiros estudantes, os melhores comportados. Eu acho que um pouco mais de presença nossa na escola, nossa eu digo não minha especificamente, mas institucional, ajudaria um pouco a corrigir isso. Eu acho que a gente precisaria abrir possibilidades para outros estudantes. Na verdade, a gente não tem tido como não ter como estudante aquela certa elite da escola pública.

Esse questionamento está presente na fala de mais um orientador: "O Pibic meio que seleciona, ele elitiza um pequeno grupo que continua 
trabalhando com pesquisa e que recebe um incentivo, mesmo que seja um valor simbólico." E outro pondera: "Então você está fechando portas para alguém que poderia ganhar com o processo, potencial pesquisador que poderia vir a se formar, se bem orientado, dentro de uma área que realmente lhe interessa". Sintetizando, é possível afirmar que os requisitos legais para seleção dos bolsistas são levados em consideração, mas há outros determinantes nas escolhas que não estão prescritos nos documentos do programa. Além disso, há questionamentos e resistências a essa dinâmica de seleção dos bolsistas, expressa por orientadores, coordenadores e coorientadores. O Pibic-EM pode ser uma oportunidade para discussão e redefinição de critérios de seleção, da política e da ideologia meritocrática presente na área educacional e científica do País.

$\mathrm{Um}$ aspecto que nos interessava era compreender os fatores intervenientes na tomada de decisão dos estudantes de participar, ou não, do Pibic-EM, isto é, o processo constitutivo das escolhas. Para isso, era preciso "buscar compreender as determinações ou as mediações" (Aguiar, 2010, p. 129) sociais. A decisão de participar do programa não é uma disposição apenas individual, precisamos entender as relações sociais que produziram esse interesse. Em algumas situações, o "acaso" foi determinante na escolha do bolsista e na sua decisão de participar do programa:

Eu participei de um concurso de cartazes, foi o terceiro concurso de cartazes sobre homo-lesbo-transfobia nas escolas [...] e meu cartaz foi um dos premiados. Na premiação a professora X conversou comigo sobre o projeto, perguntou se eu tinha interesse. Então uma bolsa caiu um pouco por acaso mesmo.

Porém, o "acaso" foi permeado por relações que convergiram para a possibilidade de ser escolhido e de escolher. O capital social e educacional desse bolsista foi constatado ao vencer um concurso que abordava temática ainda tabu em muitas escolas do País. Essa participação e a premiação permitiram um olhar atento da professora orientadora e, consequentemente, o convite ao estudante para ser seu bolsista.

O fato de ser escolhido para participar do programa carrega forte componente de percepção de pertencimento e de ser privilegiado por ser escolhido. Esse sentido de lugar acaba por dar uma direção à sua experiência. Dessa forma, há convergência entre o seu habitus e os critérios de seleção, como sinaliza um bolsista:

Eu que escolhi e fui escolhido, porque primeiramente se não parte da pessoa alguma coisa, então não consegue. Eu queria participar do projeto, queria ter uma carga teórica maior, queria ter uma chance maior de ingressar numa universidade. Então eu quis e como tive sempre um bom aproveitamento na escola, sempre fui bem na escola eles me escolheram por eu ter essa facilidade, essa carga maior de responsabilidade.

Esse processo de escolha dos que apresentam habitus e disposições mais próximas das exigidas para o campo acadêmico tem feito muitos 
orientadores optarem por alunos que já tenham sido bolsistas e que tenham experiência com pesquisa, buscando garantir "uma admissão homogênea do ponto de vista das trajetórias e dos habitus." (Valle, 2011, p. 19). Conforme afirma uma bolsista:

Acho que talvez eu tenha sido escolhida, principalmente, porque já tinha sido chamada para fazer o projeto do ano passado, da $8^{a}$ série. A professora acabou me conhecendo e, como sempre tive um contato bem grande com ela, acabou me chamando para fazer.

Há consciência sobre a condição de ter um bom rendimento na escola para se candidatar ao Pibic-EM. Uma das bolsistas reivindica bolsas para todos os interessados e não somente para os que atendem aos critérios de seleção:

Deveria abrir as portas para mais pessoas que quisessem mesmo entrar e não por causa de nota. Por que tinha que ser só 15 estudantes? Deveriam ter outras pesquisas para outros estudantes, para poder pelo menos ter uma noção do que seria.

Outro bolsista destaca a sua experiência, que foi uma ruptura dos padrões de seleção do Pibic-EM, pois era repetente e mesmo assim a orientadora acreditou nele. Essa confiança contribuiu para a melhoria do seu rendimento escolar e o seu projeto de pesquisa foi um dos destaques da escola. Ele comenta que, ao confiarem nele, deram-lhe uma chance para se superar. Desse modo, aponta como "injusto" o fato de o estudante repetente não poder participar:

Eles puxam boletim do ano passado e tanto que, em 2013, repetente não podia pegar bolsa. O que acho injusto porque, no ano que eu repeti, peguei a bolsa. Tive as maiores notas da sala e, ao mesmo tempo, a minha pesquisa foi uma das mais lidas, mais comentadas.

Somando-se a esses, há outros mobilizadores para a escolha dos bolsistas, tais como: o interesse pelo tema do projeto; a influência de familiares e amigos; as atividades realizadas com sucesso; as recompensas materiais - embora o valor da bolsa seja baixo - e simbólicas; e a relação de amizade com os orientadores. O estabelecimento de uma rede de influência favorece o conhecimento do campo acadêmico, ampliando as possibilidades de escolha dos estudantes, como destaca a bolsista:

Eu fiquei sabendo disso, porque amigos meus já tinham feito em anos anteriores. Eu acho que foi por isso. Eles falam: "Eu tenho meu certificado". Eu via que eles iam a reuniões, participavam de eventos legais, interessantes, e eu era amiga da professora, assim, bem próxima.

As escolhas são permeadas por relações que estruturam e condicionam esse processo materializado pelos envolvidos no Pibic-EM, permitindo afirmar que as escolhas apresentam elementos da individualidade e ao mesmo tempo de contexto social e econômico, envolvendo "conflito, perda, risco e coragem" (Bock, 2010, p. 219) dos candidatos. 


\section{As desistências e o desinteresse dos bolsistas pelo Pibic-EM}

Entre as razões das desistências estão aquelas relacionadas ao capital econômico, cultural e social dos bolsistas. No depoimento de um deles, podemos constatar que a necessidade de trabalhar para ajudar a família e o baixo valor da bolsa foram determinantes para a desistência do programa: "Eles desistiram pela questão financeira, porque como é escola pública tem essa questão de querer trabalhar, querer um emprego que pague mais que uma bolsa, querer ajudar os familiares em casa." Essa posição é confirmada por uma orientadora: "Iniciamos com cinco bolsistas. No outro ano passou para três e agora dois. Por quê? Porque é uma condição familiar que eles precisavam trabalhar." O valor atual das bolsas da IC na graduação é de $\mathrm{R} \$ 400,00$ e do Pibic/Júnior/EM é de R\$100,00 (Brasil. CNPq, 2013). Esse valor, para muito jovens com determinadas posições de classe e moradores das regiões do centro-sul do País, pode ser insignificante. No entanto, é preciso levar em consideração a/o repercussão/peso, na renda familiar, do valor das bolsas em algumas regiões do Brasil, como o Nordeste e o Norte, em que a renda média per capita, em 2014, foi, respectivamente, $\mathrm{R} \$ 664,00$ e $\mathrm{R} \$ 742,00$ (IBGE, 2015).

Em relação à desistência, um dos aspectos de destaque nas falas é a questão de classe social, que induz o estudante a querer trabalhar precocemente para ajudar nas despesas familiares. Essa necessidade e a prioridade para projetos de formação e de inserção no mercado de trabalho em curto prazo levaram muitos bolsistas a trocar o Pibic-EM pelo Programa Nacional de Acesso ao Ensino Técnico e Emprego (Pronatec), oferecido pelo Serviço Nacional de Aprendizagem Industrial (Senai), como afirma uma bolsista: "Porque ela faz o Senai. A diretora mandou ela escolher o Senai ou o CNPq. No Senai ela ganhava mais. Daí ela foi para o Senai." Por outro lado, há um imediatismo na decisão desses jovens, pois a maioria "busca formas (ou fórmulas) mais rápidas e eficazes de, num curto espaço de tempo, abrir as portas para o acesso incerto ao mercado de trabalho." (Ferreira et al., 2010, p. 15). Já a carreira acadêmica pressupõe disposição de médio e longo prazo para a constituição do pesquisador e para um retorno em termos econômicos, culturais e sociais.

Outro fator para a desistência do programa foi a falta de contato periódico entre orientador e orientando e o número elevado de bolsistas por orientador, dificultando o processo de orientação e acompanhamento. Segundo Leite Filho e Martins (2006), embora se referindo à PG, essa falta de contato e "consequente falta de apoio, de direcionamento e de retorno dos orientadores" (Leite Filho; Martins, 2006, p. 107) têm gerado sentimentos de insegurança, solidão e angústia. Essas questões aparecem na fala da bolsista: "Uma colega minha desistiu porque não estava dando conta do projeto e a orientadora dela também não era tão boa assim, não dava muito suporte. Ela ficou meio perdida. Então ela teve que desistir." E também aparecem na fala do orientador: "Eu acho que a gente não acertou a mão em relação àquela quantidade de gente. [...] Então alguns estudantes desistiram naquele momento." 
Dessa forma, evidencia-se que a disposição de tempo e as mediações teórico-metodológicas e atitudinais dos orientadores são decisivas para que os bolsistas construam uma trajetória de sucesso no campo acadêmico (Conceição, 2012). Além disso, o desencontro entre as expectativas de orientadores e coorientadores provocou o desligamento de bolsistas, como podemos constatar no depoimento da coorientadora:

Conversei inclusive em conselho de classe perguntando mais coisas sobre a aluna para outros professores em termos de compromisso e nós vimos que essa aluna estava totalmente enrolando a professora mesmo. Então nós pedimos para ela sair.

Sem dúvida, um dos obstáculos a superar é o despreparo dos orientadores para essa função; contudo, esse é um assunto que demanda outras pesquisas. Ainda temos a questão da especificidade da orientação de estudantes do EM, efetuada por mestres e doutores habituados a acompanhar alunos da graduação e da PG.

A dificuldade de conciliar atividades regulares da escola e demandas do Pibic-EM é maior entre aqueles que têm jornadas prolongadas do ensino médio inovador ou atividades no contraturno, provocando desistências da ICJ. O medo da reprovação, principalmente no $3^{\circ}$ ano, em que há preocupação com o vestibular e o Exame Nacional do Ensino Médio (Enem), levou à interrupção da participação no programa. Uma das bolsistas afirma que seu colega "desistiu porque não conseguia conciliar o vestibular e o Pibic." Do ponto de vista de uma coorientadora, a desistência deu-se porque "eles têm aula de tarde três dias por semana e têm muito curso sendo ofertado duas vezes por semana também."

Podemos afirmar que há ofertas e disputas pelo tempo dos jovens, por parte de diferentes instituições, como a universidade, a escola, o legislativo, as igrejas, sendo determinante, nessas escolhas, a influência do contexto familiar. O depoimento de um orientador é emblemático:

Oferta de muitas atividades as quais eles já estão vinculados. Então essa é uma atividade que demanda também tempo. As ofertas, as demandas mais variadas possíveis. Teve um estudante que era vereador mirim! [...] tinha atividades com a câmara municipal. Outros falam coisas do tipo: "ganhei uma bolsa para fazer um curso de inglês".

A dificuldade de mobilidade, pela distância e pela falta de transporte coletivo, aparece igualmente como uma das causas das desistências no depoimento de um orientador: "Morava $11 \mathrm{~km}$ da universidade, o pai não gostava de trazer, de levar, tinha problema no ônibus." Outros fatores foram: os desencontros entre as exigências e o desconhecimento dos estudantes sobre o programa; o desinteresse pelo tema e/ou pela área de pesquisa; e as dificuldades de implementar a bolsa. Uma das bolsistas pensava que o Pibic-EM "era fazer um trabalhinho, ganhar o dinheiro fácil". Outro bolsista "não tinha interesse pelo tema." Por sua vez, os orientadores relatam que os bolsistas têm "outra expectativa e são desligados porque realmente não aparecem para fazer as tarefas propostas." Desse modo, há "conflitos entre diferentes regimes, nomeadamente, o familiar, o individual 
e o institucional" (Araújo, 2009, p. 37), que produzem a desistência dos bolsistas. Esse contexto não permite afirmar que as desistências representam necessariamente insucesso, pois os estudantes podem seguir outras trajetórias de formação profissional que permitem alcançar novas posições sociais.

Ao mesmo tempo, há a percepção de que as exigências para se candidatar à bolsa (histórico escolar sem reprovações e boas notas) são obstáculos para muitos estudantes, como fala uma orientadora: "Um dos critérios apontados lá no edital é que a avaliação seja pelo histórico escolar. Isso já tira a expectativa de muitos estudantes."

O estudante com baixo rendimento escolar intui que o espaço-tempo do Pibic-EM não é seu locus, portanto, não pode fazer parte do campo acadêmico. Nesse sentido, a percepção e a disposição desses jovens reproduzem a sua posição subalterna na estrutura escolar e um sentimento de que a escola não os empodera, no sentido de lhes possibilitar disputar outras posições, por exemplo, uma bolsa do programa, como forma de preparação para a carreira acadêmica. Aliás, poucos desses jovens nutrem a expectativa de cursar a universidade, como analisa uma das orientadoras: "Para muitos aqui da região o ensino médio já é o top de linha. Eles não têm essa expectativa com curso universitário."

Na opinião de um orientador, o estudo, a pesquisa, "não é uma coisa de distinção tão importante na cultura juvenil. Ainda é visto como uma coisa de gente esquisita. É trabalhoso". O campo da investigação parece alheio a muitos estudantes. Outra questão relatada por bolsistas e orientadores em relação ao desinteresse pelo programa diz respeito à área de conhecimento disponível para pesquisa, como revela uma das orientadoras: "Talvez um estudante que tem afinidade pelas ciências humanas não me escolha como orientadora porque acha que eu vou fazer um trabalho de pesquisa com química, com fórmulas."

Assim, essas trajetórias têm repercussões nas possibilidades de alguns jovens, principalmente das classes populares, desfrutarem o tempo-espaço da "moratória social", que faz referência a

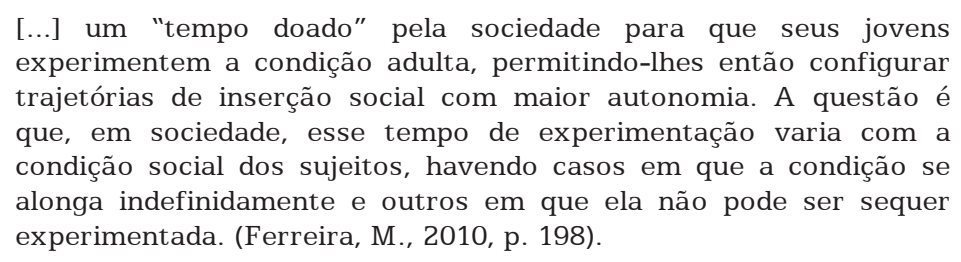
experimentem a condição adulta, permitindo-lhes então configurar trajetórias de inserção social com maior autonomia. A questão é que, em sociedade, esse tempo de experimentação varia com a condição social dos sujeitos, havendo casos em que a condição se alonga indefinidamente e outros em que ela não pode ser sequer experimentada. (Ferreira, M., 2010, p. 198).

Isso faz com que esses sujeitos vivam "a sua juventude como uma situação de trânsito e preparação para as responsabilidades da vida adulta." (Carrano, 2010, p. 150). Nesse contexto, quais jovens podem dispor da moratória social concedida pela sociedade? Os estudantes mais bem posicionados econômica, social e culturalmente têm maior possibilidade de usufruir desse excedente temporal, estando em situação distinta para constituição de projetos de formação e de carreira de longo prazo, incluindo a carreira acadêmica. 


\section{Considerações finais}

A decisão dos alunos pela entrada no Pibic-EM é composta de racionalidade no que se refere à adequação dos meios a um fim almejado, embora nem sempre explícito: o ingresso e a permanência no ensino superior e uma entrada mais rápida, certa, bem como um fluxo para a pósgraduação. Além disso, para alguns bolsistas, o programa é uma ruptura com a temporalidade inscrita na sua condição social de origem, pelo acesso a capitais sociais e culturais valorizados pela elite, possibilitando galgar novas e melhores posições na estrutura social.

O conhecimento prévio dos desafios para o acesso e a permanência no ES constitui-se uma preocupação para o bolsista. Com efeito, a "préocupação" é um elemento constituinte dos sujeitos que desejam mobilidade, incluindo os que ainda não se conformaram com a temporalidade socialmente inscrita na classe social ou, no nosso caso, na temporalidade institucional.

A ruptura que se institui na passagem para a investigação científica ou a trajetória de estudante-ouvinte para a de estudante-pesquisador iniciante é, então, uma ruptura procurada, deliberada. Essa forma antecipada de constituir planos, de procurar "bons ventos" que lhes possibilitem andar mais rápido e alcançar novas posições está explicitada nas expressões, na linguagem que os bolsistas utilizam para elencar as motivações de entrada, ao afirmarem que, com a participação, podem ter mais "noção de como vai ser; porque seria um pé lá dentro (da universidade), já teria um contato."

Os bolsistas revelam que, por meio do Pibic-EM, podem superar o medo do mitificado ambiente universitário, constituindo o desejo e apreendendo o habitus característico do campo acadêmico, ou seja, os estudantes anteveem a participação no programa como uma forma de preparação para cursar uma faculdade, para entrar em uma universidade. Os discursos dos bolsistas são ricos na forma como representam as condições para que a mobilidade se materialize mediante a passagem para o mundo universitário. Evidenciam que, para a ruptura, é necessário a aprendizagem de um habitus, de um ethos, ou a decisão de assumir/construir uma nova trajetória que ainda não dominam e que não é característica da origem social da maioria deles. Além disso, os bolsistas percebem que o ambiente escolar proporciona o acesso a esse capital social e cultural de maneira restrita. Porém, sabem que o domínio desses capitais é necessário para entrar, permanecer e concluir o ES, acessar a PG e produzir uma formação durável que lhes possibilite galgar novas posições.

Em relação à desistência e ao desinteresse dos estudantes pelo programa, há semelhanças entre as razões do abandono e as da não participação, como: baixo valor da bolsa; necessidade de trabalhar para ajudar nas despesas familiares; expectativas da família em relação à trajetória acadêmica; possibilidade de bolsa de maior valor; conciliação do programa com as atividades da escola; intuição de que não podem fazer parte do campo acadêmico pelo baixo rendimento escolar. Aqui fica manifesto que esses jovens - com baixo capital econômico, social, cultural e escolar - constatam que a escola não os prepara nem os empodera para a 
inserção qualificada no mundo acadêmico, nesse caso específico, a disputa por uma bolsa de ICJ.

Quanto aos (co)orientadores, ficou explícita a necessidade de implementar estratégias específicas para os estudantes que participam do Pibic-EM, diferenciadas daquelas que utilizam na IC da graduação e no acompanhamento de pós-graduandos.

Por fim, o pano de fundo comum, tanto do processo de escolha como das desistências e do desinteresse pelo programa, é a dependência dos jovens em relação aos "condicionamentos estruturo-societais, dada a influência da classe nas trajetórias pessoais, educacionais e profissionais" (Araújo; Jorge, 2009, p. 94). No entanto, a "juventude não é apenas uma mera consequência da estrutura" (Araújo; Jorge, 2009, p. 95). Diante disso, constatamos que muitos jovens e suas famílias criam estratégias de transgressão, para além da sua posição social original. Com todos os seus limites, o Pibic-EM ainda se apresenta como uma possível estratégia auxiliar de acesso ao ensino superior - posto que não dispensa os exames seletivos - para estudantes das camadas sociais menos favorecidas.

\section{Referências}

AGUIAR, W. M. J. A orientação profissional como espaço de produção de sentidos e desenvolvimento. In: FERREIRA, C. A. et al. (Org.).

Juventude e iniciação científica: políticas públicas para o ensino médio. Rio de Janeiro: EPSJV; UFRJ, 2010. p. 121-134.

ARAÚJO, E. R. A demora na conclusão do mestrado. In: ARAÚJO, E. R.; JORGE, A. R. O mestrado em tempo de hacking: dos tempos individuais às regulações institucionais. Porto: Prometeu Edições Ecopy, 2009. p. 37-65.

ARAÚJO, E. R.; JORGE, A. R. O mestrado em tempo de hacking: dos tempos individuais às regulações institucionais. Porto: Prometeu Edições Ecopy, 2009.

BARDIN, L. Análise de conteúdo. Lisboa: Edições 70, 1970.

BOCK, S. D. Juventude e escolha profissional. In: FERREIRA, C. A. et al. (Org.). Juventude e iniciação científica: políticas públicas para o ensino médio. Rio de Janeiro: EPSJV; UFRJ, 2010. p. 213-228.

BOURDIEU, P. Questões de sociologia. Rio de Janeiro: Marco Zero, 1983.

BOURDIEU, P. A economia das trocas linguísticas: o que falar quer dizer. São Paulo: Ed. da USP, 1998.

BOURDIEU, P. (Org.). A miséria do mundo. 5. ed. Petrópolis: Vozes, 2003. 
BRASIL. Conselho Nacional de Desenvolvimento Científico e Tecnológico (CNPq). PIBIC-EM: Programa Institucional de Bolsas de Iniciação Científica para o Ensino Médio. [2010]. Disponível em: <http://www. cnpq.br/web/guest/pibic-ensino-medio >. Acesso em: 10 mar. 2018.

BRASIL. Conselho Nacional de Desenvolvimento Científico e Tecnológico (CNPq). Bolsas e taxas no país. 2013. Disponível em: <http://www.cnpq. br/web/guest/no-pais >. Acesso em: 13 mar. 2018.

CALAZANS, J. Articulação teoria/prática: uma ação formadora. In: CALAZANS, J. (Org.). Iniciação científica: construindo o pensamento crítico. São Paulo: Cortez, 2002. p. 57-78.

CARRANO, P. C. R. O ensino médio na transição da juventude para a vida adulta. In: FERREIRA, C. A. et al. (Org.). Juventude e iniciação científica: políticas públicas para o ensino médio. Rio de Janeiro: EPSJV; UFRJ, 2010. p. 143-167.

CONCEIÇÃO, A. J. Contribuições do Programa de Iniciação Científica Júnior na Universidade Estadual de Londrina (UEL): a formação de um habitus adequado ao campo científico. 2012. 126 f. Dissertação (Mestrado em Políticas Públicas) - Centro de Ciências Humanas, Letras e Artes, Universidade Estadual de Maringá, Maringá, 2012.

CRUZ NETO, O. O trabalho de campo como descoberta e criação. In: MINAYO, M. C. S. (Org.). Pesquisa social: teoria, método e criatividade. 24. ed. Petrópolis: Vozes, 1994. p. 51-66.

FERREIRA, C. A. O programa de vocação científica da Fundação Osvaldo Cruz: fundamentos, compromissos e desafios. In: FERREIRA, C. A. et al. (Org.). Juventude e iniciação científica: políticas públicas para o ensino médio. Rio de Janeiro: EPSJV; UFRJ, 2010. p. 27-51.

FERREIRA, C. A. et al. Apresentação: contribuições para o estudo de novas perspectivas no campo da formação de jovens em ciência \& tecnologia. In: FERREIRA, C. A. et al. (Org.). Juventude e iniciação científica: políticas públicas para o ensino médio. Rio de Janeiro: EPSJV; UFRJ, 2010. p. 11-25.

FERREIRA, M. D. P. Juventude, ciência e expansão escolar: algumas questões para alimentar o debate. In: FERREIRA, C. A. et al. (Org.). Juventude e iniciação científica: políticas públicas para o ensino médio. Rio de Janeiro: EPSJV; UFRJ, 2010. p. 193-212.

FILIPECKI, A.; BARROS, S. S.; ELIA, M. F. A visão dos pesquisadoresorientadores de um programa de vocação científica sobre a iniciação científica de estudantes de ensino médio. Ciência \& Educação, Bauru, v. 12, n. 2, p. 199-217, 2006. 
FREIRE, P. Pedagogia do oprimido. Rio de Janeiro: Paz e Terra, 2005.

INSTITUTO BRASILEIRO DE GEOGRAFIA E ESTATÍSTICA (IBGE). IBGE divulga renda domiciliar per capita 2014. Rio de Janeiro, 2015. Disponível em: <ftp://ftp.ibge.gov.br/Trabalho_e_Rendimento/Pesquisa_ Nacional_por_Amostra_de_Domicilios_continua/Renda_domiciliar_per_ capita/Renda_domiciliar_per_capita_2014.pdf >. Acesso em: 12 mar. 2018.

LEITE FILHO, G. A.; MARTINS, G. A. Relação orientador-orientando e suas influências na elaboração de teses e dissertações. RAE: Revista de Administração de Empresas, São Paulo, v. 46, p. 99-109, nov./dez. 2006. Edição especial.

LUDKE, M.; ANDRÉ, M. E. D. A. Pesquisa em educação: abordagens qualitativas. São Paulo: EPU, 1988.

OLIVEIRA, A.; BIANCHETTI, L. Iniciação científica: possibilidades e limites à instauração de um círculo virtuoso. Educação em Perspectiva, Viçosa, v. 8, n. 1, p. 3-19, jan./abr. 2017.

SCORSOLINI-COMIN, F. Guia de orientação para iniciação científica. São Paulo: Atlas, 2014.

VALLE, I. R. Apresentação. In: BOURDIEU, P. Homos academicus. Florianópolis: Ed. da UFSC, 2011. p. 13-20.

Recebido em 13 de março de 2018.

Aprovado em 15 de fevereiro de 2019. 